\title{
DIVERSIDADE, CIDADANIA E DIREITOS: UMA CONCEPÇÃO DE FORMAÇÃO DO PROFESSOR
}

\author{
Andréa Kochhann ${ }^{1}$ \\ Alice Carlos Feliciano ${ }^{2}$ \\ Patrícia Ramiro ${ }^{3}$ \\ Vanessa Amélia da Silva Rocha ${ }^{4}$
}

\section{INTRODUÇÃO}

Este artigo foi elaborado com base nas experiências de uma professora e de acadêmicos que cursaram uma determinada disciplina e também de acadêmicos que não cursaram a disciplina. A disciplina em questão é a "Diversidade, Cidadania e Direitos", que fora implantada no currículo dos cursos de licenciatura da Universidade Estadual de Goiás - UEG.

O interesse da UEG ao inserir a disciplina na matriz curricular de 2015, é que os futuros professores tenham maior consciência cidadã e sejam resilientes, melhorando sua atuação pedagógica. Almeja-se que tenham além de qualidade de conhecimento, consciência de si e do outro, multiplicando e acreditando na sua formação e na sociedade.

\section{METODOLOGIA}

A disciplina foi ministrada para o $1^{\circ}$ ano de matemática, com 18 alunos, sendo que a media da idade deles era de 20 anos, no período noturno nos dias de quinta-feira das 19:00 as 22:30. A metodologia utilizada foi aulas expositivas

\footnotetext{
${ }^{1}$ Docente efetiva da Universidade Estadual de Goiás. Doutoranda em Educação pela Universidade de Brasília - Brasil. andreakochhann@yahoo.com.br

${ }^{2}$ Acadêmica do curso de Matemática da Universidade Estadual de Goiás Câmpus Jussara - Brasil. alicecarlosfeliciano@gmail.com

${ }^{3}$ Acadêmica do curso de Matemática da Universidade Estadual de Goiás Câmpus Jussara Brasil.patriciaramirocarlos@gmail.com

${ }^{4}$ Acadêmica do curso de Matemática da Universidade Estadual de Goiás Câmpus Jussara Brasil.vanessa-amelia-silva@hotmail.com
} 
dialogadas, roda de conversa, apresentação de seminário, com palestras, com aulas técnicas, com visitas campo, elaboração midiática e de uma revista pedagógica.

\section{RESULTADOS E DISCUSSÃO}

A Universidade Estadual de Goiás, constituiu ao longo dos anos de 2013 e 2014 o NDE - Núcleo de Desenvolvimento Estruturante em todos osCâmpuspara avaliar e reorganizar as matrizes curriculares de todos os curso dessa instituição, após debates em cada campus e em cada curso, ocorrem os debates regionais.

O resultado deste trabalho foi a inserção da disciplina "Diversidade, Cidadania e Direitos" em todos os cursos de licenciatura da UEG, além de outras mudanças curriculares. Uma das componentes do NDE relatou durante reuniões do GEFOPI que, o objetivo desta disciplina é favorecer a conscientização e mudança de atitudes, dos acadêmicos da UEG, visto que serão formadores de opinião em seu trabalho pedagógico.

A relação homem-natureza têm sido cada dia mais degradante. Assim, os cursos de licenciatura devem discutir sobre como deve ser a relação homemnatureza. Destarte a consciência de que seu papel não é de mero (re)produtor de conteúdos, mas de formador de homens.

Com essa expectativa a ementa escolhida para a referida disciplina foi "Diversidade: cultura, gênero, etnia, raça e desigualdades sociais. Noções sobre formação da cultura brasileira. Relações étnicos-raciais. Respeito e valorização das diferenças culturais, sociais e individuais. Cidadania: concepções, garantias e práticas. Estado Democrático de Direito, democracia, movimentos sociais e cidadania. Constitucionalismo e Direitos: concepções, violações, promoção, defesa e garantias. Evolução do conceito: dos direitos de liberdade planetário a à sustentabilidade.".

Como pode ser percebido pela ementa, não é possível aprofundar teoricamente em cada assunto. Assim, foi escolhido trabalhar com uma dinamicidade na prática pedagógica para que os acadêmicos tivessem um olhar e 
uma sensibilidade despertada e que se aprimorassem em outro momento. O plano de trabalho foi elaborado em conjunto com os acadêmicos.

Com a turma que cursou a disciplina realizou-se um debate introdutório,paradiscutir questões iniciais da disciplina como Inclusão Escolar, Emancipação Humana, Inculcação ideológica, Meio Ambiente e entre outros. Analisou-se textos científicos e realizamos seminários no momento da discussão teórica. Elaborou-se resenhas críticas, rodas de conversas, análise de filmes e slides como produção midiática e científica. Nesse debate todos falavam aleatoriamente 0 que entendiam de cada tema e aos poucos os colegas complementavam e a professora finalizava. Essa dinâmica foi para sensibilizar os alunos sobre as temáticas que precisam conhecer para seu trabalho pedagógico e enquanto cidadãos.

Para as palestras convidou-se profissionais de cada área que julgamos importante a ementa. O primeiro palestrante foi o presidente do Conselho Tutelar de uma cidade vizinha, que discutiu sobre a violência contra menores e o estatuto da criança e do adolescente. A participação dos acadêmicos no debate foi interessante e os esclarecimentos sobre alguns pontos foram importantes.

Outra palestra foi com uma advogada que discutiu a constituição e o código penal relativos aos temas da disciplina. Muitos não conheciam o código penal e várias questões emergiram. Saber os direitos e deveres do cidadão se torna importante para aprendermos a nos comportar na sociedade. As punições são percebidas como necessárias perante uma sociedade em que não se tem consciência humanitária.

Também tivemos uma palestra com um diretor prisional que apresentou os direitos e os deveres dos detentos, mostrou com imagens com é o espaço prisional que dirige e explicou como é o tratamento humanitário dispensado aos detentos, uma representante do governo estadual que discute direitos humanos. Para esse diretor, toda pessoa, mesmo que seja um detento, é um ser humano e precisa ser tratado como tal. Emmuitos casos os detentos saem da prisão mais negligentes do que entraram.

Para finalizar o ciclo de palestras convidamos uma representante da SEMIRA - Secretaria da Mulher, do Desenvolvimento Social, da Igualdade Racial, dos Direitos Humanos e do Trabalho. A discussão travada foi a mais intensa e polêmica. Principalmente quando abordou-se o assunto da homofobia e da 
transsexualidade e dos direitos já adquiridos pelas pessoas que tem uma relação homoafetiva.

Participamos de um dia de campo momento que visitamos três ambientes distintos e com culturas humanitárias também distintas. Visitamos a Vila São Cottolengo, em Trindade - GO. A vila é um espaço de moradia permanente de mais de 300 pessoas que foram abandonadas por seus familiares e apresentam algum distúrbio. A equipe multidisciplinar de profissionais que cuidam desses moradores nos passou uma lição de vida e cidadania. A relação entre eles é de extrema afetividade e amor. O respeito é muito grande pelo ser humano.

Visitamos também o shopping Passeio das Águas, em Goiânia - GO. Muitos acadêmicos não conheciam shopping. Foi a oportunidade para discutirmos sobre as diferenças existentes entre uma cidade do interior e uma capital. As diferenças são gritantes, tanto em relação ao espaço físico, quanto em relação às pessoas que frequentam o ambiente e aos locais de alimentação. Uma cultura diferente.

Por fim, conhecemos o cinema. Assistimos ao filme "Linda de morrer", que apesar de uma comédia retrata a realidade de muitas famílias que buscam desenfreadamente o dinheiro para dar estabilidade a família, mas se esquecem dos princípios familiares. O filme mostra que o amor e o convívio familiar não depende das posses financeiras.

Como forma de avaliação, dividimos a turma em quatro grupos para a elaboração de uma revista. Após caloroso debate, foram escolhidos os temas a serem abordados na revista. Em seguida iniciou-se a elaboração das quatro revistas pedagógicas com o tema central n“Consciência”, usando o Publisher.

A revista pedagógica "Obesidade infanto juvenil" aborta os riscos da obesidade nas crianças, os preconceitos que elas sofre, contém também umrelato de experiência. Uma entrevista com umanutricionista falando a importância de uma boa alimentação, qual seu papel na sociedade, quais os principais erros cometidos numa dieta entre outros.

Outra revista tratou do tema Sustentabilidade, onde é abordados assuntos como: O que é Sustentabilidade? O que é biodigestor? E também como que se pode atribuir os 3Rs em nossa sociedade. O objetivo dessa revista é a conscientização das pessoas referente às ações que refletem diretamente no meio ambiente. Nessa revista contém artigo de opinião e cientifico, entrevista e passa tempo e outros. 
A revista pedagógica "Incluir" aborta o tema o que e inclusão?Também fala sobre inclusão nas escolas, pessoas com deficiências e suas dificuldades no mercado de trabalho contem também relatos de experiências, histoórias de vidas, reportagem indicações de filmes, livros e outros.

A revista pedagógica "Violência em tudo e em todos" aborda um tema bastante polemico que e as violências contra a mulher alem de aborda também a violência contra o homem, criança, delinquência juvenil, bullying. Contendo relato de experiência, entrevistas, informativos sobre como denunciar as violências, indicações de filmes e livros sobre violência que pode ser trabalhado nas escolas.

As revistas serão usadas para enquanto um projeto de extensão, em visitas as escolas da região para discutir os temas das mesmas. Também as revistas serviram para apresentação em um evento regional, o EREPPEGO - Encontro Regional de Ensino, Pesq uisa e Prática Pedagógica do Goiás, realizado pela Universidade Estadual de Goiás Câmpus Jussara.

Os acadêmicos que cursaram essa disciplina socializaram nos encontros do GEFOPI o quão valioso foi o trabalho durante o semestre, para o seu reconhecimento enquanto cidadão e como pessoa que se relaciona com outras pessoas e com a natureza. A consciência da diversidade, da cultura, de cidadania e de direitos, segundo as acadêmicas, pode favorecer uma relação entre professor e aluno, não apenas de conteúdos, mas de humanidade. Como apresentado anteriormente, esta disciplina foi ofertada a partir de 2015.

Os acadêmicos que ingressaram em períodos anteriores a este não cursaram essa disciplina. Nos encontros do GEFOPI, duas acadêmicas que não cursaram a disciplina, deram o depoimento de que percebem que o estudo desses temas é de extrema relevância para suas formações enquanto futuros professores. Alegaram que foi uma grande perca não terem essa disciplina, visto que a formação acadêmica deve ser composta de discussõessobre cidadania, diversidade, cultura, inclusão, entre outros. Afirmaram ainda que um professor com uma concepção aberta sobre essas questões pode respeitar mais as pessoas que apresentam como diferentes. Além do mais todos são cidadãos e iguais perante a natureza, com quem mantêm um diálogo harmonioso ou não.

A professora da disciplina socializou que teve grande experiência pela dinamicidade que tratou a mesma e que sente a necessidade de reavaliar sua prática pedagógica nas outras disciplinas que ministra. Para além da docência, 
também afirmou que seu crescimento foi como ser humano, que valoriza mais o próximo e a família.

O interesse dos componentes do GEFOPI é de socializar as experiências dos acadêmicos de Matemática, da UEG, Câmpus Jussara, com a intenção de conscientizar o público e quiçá gestores que nos assistam e leiam nossos trabalhos, posam refletir sobre a formação que desejam para o professor e inserir na matriz curricular disciplinas como a "Diversidade, Cidadania e Direitos".

\section{CONSIDERAÇÕES}

A sociedade e o homem se transformam a cada dia. A educação precisa acompanhar essas mudanças. O processo de formação do professor deve ser pensado nessa perspectiva. Portanto, os projetos pedagógicos dos cursos e suas matrizes curriculares, devem apresentar disciplinas que favoreçam acompanhar as vicissitudes da humanidade.

Destarte, a UEG preocupada com a formação de professores e com sua missão, que é a transformação social, inseriu a disciplina Diversidade, Cidadania e Direitos, em todos os cursos de licenciatura. Apesar de ser o primeiro ano de experiência, com uma educação mais voltada para a cidadania na formação do professor já é possível afirmar que a jornada é relevante e as conquistas virão com o passar dos anos, no seio da nossa sociedade pela relação homem-natureza.

\section{REFERÊNCIAS}

CORTELLA, Mário Sérgio. A ESCOLA E O CONHECIMENTO: fundamentos epistemológicos e políticos. 12. ed. rev. e ampl. São Paulo: Cortez, 2008.

FREITAS, Carla Conti de. SUSTENTABILIDADE NO ENSINO SUPERIOR: uma prática transdisciplinar na formação de professores. 2. ed. Goiânia: Kelps, 2010.

MANTOAN, M. T. INCLUSÃO ESCOLAR: o que é? Por quê? Como fazer? São Paulo: Summus, 2015.

REIS, Marlene Barbosa de Freitas. DOCÊNCIA UNIVERSITÁRIA: práticas interdisciplinares no Ensino Superior. 2. Anápolis: UEG, 2014. 
SILVA, T.T. IDENTIDADE E DIFERENÇA: a perspectiva dos estudos culturais. Petrópolis: Vozes, 2000.

TONET, I. EDUCAÇÃO, CIDADANIA E EMANCIPAÇÃO HUMANA. Ijuí: UNIJUI, 2005.

\section{FONTES FINANCIADORAS}

Universidade Estadual de Goiás com bolsa PIBID e apoio financeiro a eventos pelo Edital Pró-Eventos 